Original Research Paper

\title{
Peningkatan Pengetahuan Studi Etnomedisin Pada Mahasiswa Farmasi
}

\author{
Nisa Isneni Hanifa ${ }^{1 *}$, Agriana Rosmalina Hidayati ${ }^{1}$, Anggit Listyacahyani Sunarwidhi ${ }^{1}$, Dyke Gita \\ Wirasisya $^{1}$ \\ ${ }^{1}$ Program Studi Farmasi, Fakultas Kedokteran, Universitas Mataram, Mataram, Indonesia.
}

https://doi.org/10.29303/jpmpi.v3i2.1240

Sitasi: Hanifa, N. I., Hidayati, A. R., Sunarwidhi, A. L \& Wirasisya, D. G. (2021). Peningkatan Pengetahuan Studi Etnomedisin Pada Mahasiswa Farmasi. Jurnal Pengabdian Magister Pendidikan IPA 4(4)

\section{Article history}

Received: 19 Oktober 2921

Revised: 30 Oktober 2021

Accepted: 30 November 2021

*Corresponding Author: Nisa

Isneni Hanifa, Program Studi Farmasi, Fakultas Kedokteran, Universitas Mataram, Mataram, Indonesia;

Email:

nisa.isneni.hanifa@unram.ac.id

\begin{abstract}
The topic of research on the exploration of natural materials is still a favorite among pharmacy students. This is also supported by the biodiversity in Indonesia which is spread across the region. Students need more insight and description of research topics related to natural product products, one of which is ethnomedicine studies. Based on this background, it is necessary to provide education related to ethnomedicine studies from experts to increase students' knowledge about the topic of exploring medicinal herbs and plants from ethnic groups in Indonesia. Education is carried out using lecture and discussion methods in webinars using virtual meeting applications with pretest and posttest. The webinar was attended by 239 participants, with the majority being pharmacy students from several Indonesian pharmacy universities. From the results of the pretest, it is known that the average knowledge of participants about ethnomedicine is 53.89. After the expert's explanation, the participants' knowledge increased with the average post-test score of 71.21. Participants' knowledge of the ethnomedicine study increased after being given education.
\end{abstract}

Keywords: Education; Ethnomedicine studies; Pharmacy students.

\section{Pendahuluan}

Indonesia adalah salah satu negara yang mempunyai mega diversity spesies hayati dan mega-center keragaman hayati dunia. Keanekaragaman hayati Indonesia sebanding dengan Brazil yang mempunyai daratan lebih dari 5 kali besarnya (Indrawan et al., 2007). Obat berbahan baku alam Indonesia memang saat ini merupakan komoditas prioritas yang dikembangkan pemerintah. Di bawah koordinasi Menteri Koordinator Bidang Pembangunan Manusia dan dan Kebudayaan, Badan POM telah menginisiasi pembentukan "Satuan Tugas (Satgas) Percepatan Pengembangan dan Pemanfaatan Jamu dan Fitofarmaka" yang terdiri atas lintas sektor, antara lain asosiasi pelaku usaha, perguruan tinggi, peneliti, dan pelaku usaha (BPOM, 2020).
Seiring dengan tren back to nature dan semakin mudahnya mendapatkan informasi di era digital ini, terdapat suatu pola pada masyarakat umum untuk cenderung menggunakan produkproduk yang berbasis bahan alam atau dibuat dari bahan alam untuk memenuhi kebutuhannya. Mulai dari produk kosmetik dan skin care, hingga produkproduk untuk pengobatan sendiri (swamedikasi). Mayoritas masyarakat Indonesia meyakini bahwa produk bahan alam jauh lebih aman dan tanpa efek samping dibandingkan obat sintetis. Sebagaimana diketahui, penggunaan produk bahan alam untuk pengobatan tidak sepenuhnya selalu aman, tetap memiliki efek samping dan dapat berbahaya jika penggunaannya tidak benar atau produknya mengandung senyawa berbahaya. Hal tersebut disebabkan karena pada dasarnya senyawa aktif 
berkhasiat dalam obat herbal juga merupakan senyawa kimia, sehingga diperlukan pemahaman bahwa apabila penggunaannya tidak benar, maka juga dapat menyebabkan efek samping yang berbahaya seperti pada obat sintetis (Program Studi Kimia ITB, 2011).

Selain keanekaragaman hayati, Indonesia juga kaya akan keanekaragaman suku dan budaya. Data Sensus Penduduk Badan Pusat Statistik (BPS) tahun 2010 menyebutkan bahwa ada 1.331 suku yang tersebar di Indonesia (Badan Pusat Statistik, 2015). Setiap suku memiliki kearifan lokal masingmasing, termasuk pemanfaatan tumbuhan dalam ramuan untuk pengobatan. Hasil Riset Tumbuhan Obat dan Jamu (RISTOJA) (2017) menunjukkan bahwa terdapat 6.193 ramuan yang digunakan untuk mengatasi 74 jenis penyakit/gejala yang berhasil didata dari 100 etnis di 11 provinsi di Indonesia. Sebanyak 9.516 tumbuhan obat yang berhasil diidentifikasi dan sebagian besar diperoleh di sekitar rumah.

Mahasiswa farmasi sebagai pembelajar dan agent of change memiliki semangat yang tinggi untuk mendalami ilmu kefarmasian. Topik penelitian mengenai eksplorasi bahan alam untuk berbagai efek farmakologis laris manis di kalangan mahasiswa. Pengembangan sediaan farmasi dengan bahan baku dari bahan alam juga terus dilakukan. Melihat antusiasme mahasiswa dalam melakukan penelitian terkait bahan alam, mendorong kami untuk melakukan edukasi mahasiswa farmasi terkait topik penelitian eksplorasi ramuan dan tumbuhan obat dari pengetahuan etnis tertentu atau yang kerap dikenal dengan studi etnomedisin.

Hingga saat ini belum ada kegiatan pengabdian kepada masyarakat untuk mengedukasi mahasiswa terkait studi etnomedisin. Studi etnomedisin telah dilakukan oleh peneliti untuk menggali pengobatan tradisional pada berbagai etnis, beberapa diantaranya di Lombok (Wirasisya et al., 2020), Sumatera Barat (Silalahi et al., 2020), dan Kabupaten Wajo (Umar, 2006). Edukasi ini penting dilakukan agar mahasiswa lebih siap untuk menjalankan penelitian dan penggalian informasi tumbuhan obat yang digunakan oleh masyarakat dalam ramuan obat tradisional. Selain itu, topik ini juga akan mendukung program pemerintah untuk menginventarisasi tumbuhan asli Indonesia yang berkhasiat obat dan juga mencari tumbuhan yang potensial sebagai penghasil senyawa bioaktif baru yang memiliki efek farmakologis. Harapan jangka panjang, hasil studi etnomedisin dapat dijadikan dasar pengembangan produk jamu, obat herbal terstandar (OHT), maupun fitofarmaka.

\section{Metode}

Bentuk kegiatan pengabdian masyarakat ini berupa edukasi tentang studi etnomedisin. Edukasi akan dilaksanakan dalam bentuk seminar online menggunakan aplikasi virtual meeting. Adapun pendekatan yang akan digunakan adalah edukatif, yaitu pendekatan yang dalam program maupun pelaksanaan pengabdian mengandung unsur pendidikan yang dapat mendinamisasikan masyarakat menuju kemajuan yang dicita-citakan. Sasaran kegiatan pengabdian kepada masyarakat adalah mahasiswa farmasi, khususnya yang ada di wilayah Provinsi NTB. Karena media yang akan digunakan adalah virtual meeting, maka peserta dan narasumber langsung dapat berinteraksi selama acara terutama pada sesi tanya jawab.

Edukasi disampaikan dengan bantuan media berupa power point dan gambar. Evaluasi keberhasilan kegiatan dilihat dari bagaimana respon peserta selama kegiatan berlangsung terutama keaktifan peserta pada sesi tanya jawab. Selain itu, evaluasi juga dilakukan dengan menilai pengetahuan peserta sebelum dan setelah memperoleh materi. Sebelum materi dimulai, peserta diberikan pretest untuk mengetahui sejauh apa wawasan peserta terhadap tema yang diangkat. Di akhir acara dilaksanakan post-test dengan soal yang sama untuk melihat peningkatan pengetahuan peserta terhadap materi yang disampaikan.

\section{Hasil dan Pembahasan}

Kegiatan pengabdian kepada masyarakat yang bertema "Studi Etnomedisin: Eksplorasi Tanaman Obat Tradisional" telah dilakukan oleh tim pengabdian kelompok keilmuan biologi farmasi Universitas Mataram. Kegiatan ini dilaksanakan pada hari Sabtu, 4 September 2021 pukul 10.00- 


\subsection{WITA menggunakan platform Zoom}

Meeting. Peserta yang mengikuti kegiatan webinar ini sebanyak 239 orang, dimana jumlah ini berhasil mencapai target, bahkan melebihi target yang telah ditetapkan di awal, yaitu 100 orang. Peserta yang hadirpun tidak hanya dari kalangan mahasiswa, namun juga dari kalangan dosen dan laboran farmasi, serta tenaga kesehatan di puskesmas. Mayoritas peserta berasal dari Perguruan Tinggi Farmasi (PTF) di Mataram, NTB, namun beberapa peserta berasal dari PTF di luar kota, seperti Yogyakarta, Jember, Palangkaraya, Makassar dan Palu. Peserta pada kegiatan ini dapat dilihat pada gambar 1.

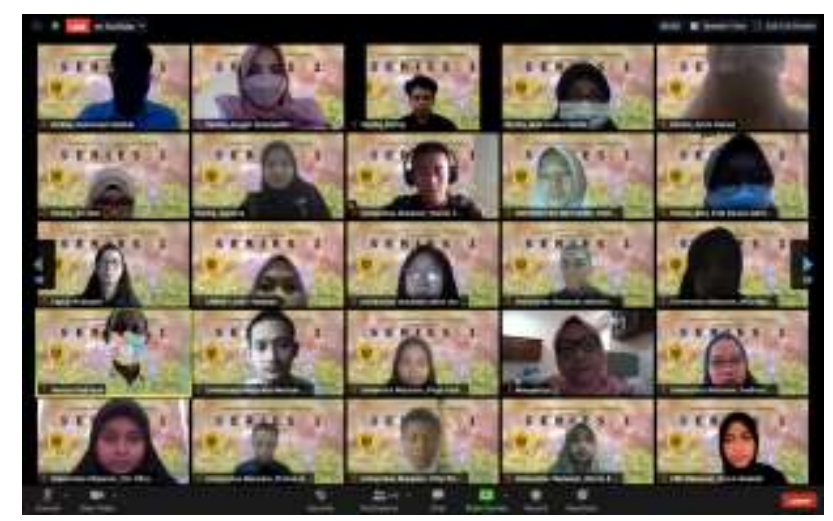

Gambar 1. Peserta kegiatan pengabdian kepada masyarakat "Studi Etnomedisin: Eksplorasi Tanaman Obat Tradisional"
Kegiatan ini dimulai dengan pengisian daftar hadir dan soal pretest oleh peserta untuk mengukur wawasan awal peserta terhadap tema studi etnomedisin. Pasca mengisi pretest, materi disampaikan oleh pakar di bidang herbal, yaitu Prof. Dr. apt. Mangestuti Agil, M.S., yang merupakan guru besar di bidang farmakognosi salah satu universitas negeri di Surabaya. Narasumber menjelaskan tentang apa itu etnomedisin dan etnobotani, bagaimana merancang studi etnomedisin, faktor natural dan supernatural etiologi penyakit, parameter yang perlu diperhatikan atau digali pada studi etnomedisin, dan contoh studi etnomedisin yang pernah dilakukan, baik di Indonesia maupun di luar negeri.

Peserta sangat antusias mengikuti acara ini, dan hal ini terlihat pada sesi pemaparan materi dimana peserta menyimak dengan baik dan menyampaikan komentar serta pertanyaan melalui kolom chat Zoom Meeting. Pada sesi tanya jawab, peserta juga diperkenankan bertanya secara langsung kepada narasumber. Beberapa pertanyaan dari peserta dan penjelasan yang disampaikan oleh narasumber tertuang pada tabel 1 .

Tabel 1 Pertanyaan dan penjelasan yang disampaikan pada sesi tanya jawab

\begin{tabular}{ll}
\hline No & \multicolumn{1}{c}{ Pertanyaan } \\
\hline 1 & $\begin{array}{l}\text { Apakah penelitian terkait penggunaan sirih pada } \\
\text { masyarakat dapat saya lakukan? }\end{array}$
\end{tabular}

Penjelasan dari narasumber masyarakat dapat saya lakukan?

Penelitian mengunyah sirih sudah banyak dilakukan. Banyak penelitian ilmiah yang tidak mendukung, dikarenakan efek samping yang dapat ditumbulkan. Perlu dilakukan studi literatur yang lebih mendalam lagi terkait topik ini. Jika jenis sirihnya istimewa dan hanya tumbuh di daerah itu saja, dan dapat dibandingkan senyawa aktifnya lebih unggul dibandingkan daerah lain, maka akan menjadi keunggulan dari penelitian tersebut.

2 Banyaknya terminology yang digunakan di dalam studi etnomedisin ini. Apakah semua sama atau berbeda? Terkait mind soul body, bagaimana caranya memasukkan ini ke dalam penelitian?

3 Kami meneliti tanaman widuri untuk cacingan, namun setelah turun ke masyarakat, bahan yang digunakan untuk analgesik atau pereda sakit gigi, yang ditemukan pun hanya berwarna ungu, khawatirnya tidak terbukti dengan studi literature dan penggunaan oleh masyarakat?

Pendekatan saja yang perlu diperhatikan, yaitu antropologi, selanjutnya ingin difokuskan ke mana sangat ditentukan pada apa yang ingin diteliti. Sebaiknya tidak berhenti hanya pada listing tanaman.

Ketika penggunaannya ternyata berbeda di lapangan, penelitian tetap dilanjutkan saja dengan menggali informasi lebih mendalam lagi ke narasumber. Di dalam studi etnomedisin kita dapat mendeskripsikan dari berbagai sudut pandang. 


\begin{tabular}{|c|c|c|}
\hline No & Pertanyaan & Penjelasan dari narasumber \\
\hline 4 & $\begin{array}{l}\text { Kami sempat penelitian etnomedisin di daerah } \\
\text { Lombok Timur, kami menggunakan pemandu, } \\
\text { bagaimana kami bisa menvalidasi apa yang } \\
\text { dikatakan oleh pemandu? }\end{array}$ & $\begin{array}{l}\text { Validasi pemandu dan pengobat harus terus digali dengan } \\
\text { mendalam. }\end{array}$ \\
\hline 5 & $\begin{array}{l}\text { Pengobatan tradisional menjadi salah satu } \\
\text { alternatif pengobatan bagi sebagian masyarakat, } \\
\text { semisal pengobatan patah tulang yang menurut } \\
\text { beberapa kasus harus dilakukan amputasi, namun } \\
\text { ketika ditangani oleh pengobat tradisional justru } \\
\text { malah sembuh. Di sisi lain, obat-obat tradisional } \\
\text { seperti minyak urut (minyak sumbawa) juga } \\
\text { memiliki tempat khusus di tengah masyarakat } \\
\text { akibat manfaatnya. Permasalahannya adalah } \\
\text { terkait standarisasi. pengobat ataupun obat }\end{array}$ & $\begin{array}{l}\text { Kerjasama antara para pengobat dengan unsur perguruan } \\
\text { tinggi sangat penting. Contoh penelitian etnomedisin di } \\
\text { Madura, sebaiknya harus ada perhatian pemerintah dalam } \\
\text { pelaksanaan penelitian ini. Perguruan tinggi jika ingin } \\
\text { melakukan penelitian dengan pengobat dengan niat yang } \\
\text { benar-benar baik seringkali dapat diterima oleh para } \\
\text { pengobat. Kita perlu banyak belajar dari Negara lain, seperti } \\
\text { India yang bahkan sudah memiliki kementrian khusus untuk } \\
\text { pengobatan Ayuverda. }\end{array}$ \\
\hline
\end{tabular}

terkait standarisasi, pengobat ataupun oba tidak banyak yang dapa distandarisasi sesuai keilmuan modern. Kira-kira bagaimana peran khususnya para peneliti etnomedisin/etnobotani untuk membawa para pengobat atau obat tradisional tersebut bisa memperoleh standarisasi sehingga bisa diakui secara umum dan bagi para pengobat mereka bisa berpraktik secara terbuka?

6 Bagaimana pertimbangan dalam penentuan metode sampling dalam studi etnomedisin dan etnobotani?

7 Dalam melakukan studi etnomedisin, dasar pemilihan daerah/lokasi, apakah ada batasan ukuran wilayah yang harus diteliti?

$8 \quad$ Apakah ada tips \& trik khusus saat melakukan wawancara kepada narasumber, agar diterima baik dan tidak ditolak saat diwawancarai?

Metode yang digunakan ini bisa mendapatkan sebanyak mungkin informasi dari sebanyak mungkin informan, dengan metode snowball, sampai tidak ada lagi yang dapat memberikan informasi.

Ketentuan wilayah tergantung dari banyak hal. Dengan Perkembangan IPTEK, keterbatasan wilayah ini dapat diatasi.

Perlu trik dan pengalaman, jangan sampai kita menimbulkan kesan bahwa peneliti ingin merampok resep yang dimiliki oleh pengobat.

Setelah sesi tanya jawab selesai, peserta diminta mengisi post test dengan soal yang sama dengan pretest untuk mengukur peningkatan pengetahuan peserta terhadap materi. Selain itu, data ini juga digunakan untuk mengevaluasi keberhasilan kegiatan ini. Sebanyak 10 soal pada pretest dan post-test menggali pengetahuan peserta seputar etnomedisin dan teknik penelitiannya. Nilai pretest dan post-test peserta dapat dilihat pada tabel 2.

Tabel 2. Nilai pretest dan post-test peserta

\begin{tabular}{lcccc}
\hline Evaluasi & Mean & Median & $\begin{array}{c}\text { Nilai } \\
\text { Min }\end{array}$ & $\begin{array}{c}\text { Nilai } \\
\text { Max }\end{array}$ \\
\hline Pretest & 53.89 & 50 & 0 & 90 \\
\hline Post-test & 71.21 & 70 & 20 & 100 \\
\hline
\end{tabular}

Pada tabel 2 terlihat adanya perubahan pengetahuan sebelum dan sesudah pemberian materi oleh narasumber. Nilai rata-rata pretest sebesar 53.89 dari 239 peserta menunjukkan nilai yang kurang baik karena nilai tersebut kurang dari 56. Berdasarkan hasil ini, artinya rata-rata pengetahuan awal peserta terkait studi etnomedisin masih kurang baik. Setelah pemberian materi dan sesi tanya jawab, nilai rata-rata post-test naik menjadi 71.21 dan masuk dalam kategori nilai yang baik. Nilai ini menunjukkan bahwa pemberian materi dan penjelasan mendalam dari narasumber dapat meningkatkan pengetahuan peserta terkait studi etnomedisin. Parameter nilai minimum dan maksimum yang diperoleh peserta saat pretest dan post-test, juga menunjukkan perubahan kearah peningkatan pengetahuan peserta. 


\section{Kesimpulan}

Kegiatan pengabdian kepada masyarakat berupa edukasi tentang "Studi Etnomedisin: Eksplorasi Tanaman Obat Tradisional" telah dilaksanakan dengan 239 peserta mahasiswa, dosen dan laboran farmasi. Kegiatan edukasi ini berhasil meningkatkan pengetahuan peserta terkait studi etnomedisin dengan rata-rata nilai pretest dan posttest peserta berturut-turut sebesar 53.89 dan 71.21.

\section{Saran}

Agar mahasiswa mendapatkan pengalaman praktis terkait studi etnomedisin, dapat dilakukan pelatihan merancang studi etnomedisin secara offline hingga ada simulasi wawancara pada pengobat tradisional.

\section{Ucapan Terima Kasih}

Penulis mengucapkan terima kasih kepada Program Studi Farmasi Fakultas Kedokteran Universitas Mataram yang telah memberi dukungan financial terhadap pengabdian ini.

\section{Daftar Pustaka}

Badan Pusat Statistik. (2015). Mengulik Data Suku $d i$ Indonesia. https://www.bps.go.id/news/2015/11/18/127/ mengulik-data-suku-di-indonesia.html

BPOM. (2020). Bursa Hilirisasi Inovasi Herbal Indonesia 2020: Pertemuan Peneliti dan Pelaku Usaha untuk Percepat Pengembangan Herbal Indonesia. https://www.pom.go.id/new/view/more/berita/ 17945/Bursa-Hilirisasi-Inovasi-HerbalIndonesia-2020--Pertemuan-Peneliti-danPelaku-Usaha-untuk-PercepatPengembangan-Herbal-Indonesia.html

Indrawan, M., Primack, R. B., \& Supriatna, J. (2007). Biologi Konservasi. Yayasan Obor Indonesia.

Program Studi Kimia ITB. (2011). Obat Herbal. http://www.chem.itb.ac.id/obat- herbal

Silalahi, M., Khairiah, A., \& Nisyawati. (2020). Ethnomedicinal plants and practices related to pregnancy, childbirth, and postpartum healthcare of minangkabau ethnic group, West Sumatra, Indonesia. Biodiversitas, 21(10),
4597-4605.

https://doi.org/10.13057/biodiv/d211018

Umar, M. R. (2006). Keanekaragaman spesies tumbuhan berhasiat obat yang dimanfaatkan masyarakat Desa Paselloreng, Kabupaten Wajo. Prodising Seminar Nasional Pengelolaan Sumberdaya Dan Keanekaragaman Hayati Secara Berkelanjutan.

Wahyono, S., Widowati, L., Mujahid, R., Subositi, D., Widiyastuti, Y., Haryanti, S., Junediono, Jokopriyambodo, W., Budiarti, M., Maruzy, A., Mustofa, F. I., \& Sari, A. N. (2017). Laporan Riset Khusus Eksplorasi pengetahuan lokal etnomedisin dan tumbuhan obat berbasis komunitas di Indonesia.

Wirasisya, D. G., Hanifa, N. I., \& Hajrin, W. (2020). Ethnobotanical Study of Medicinal Plants Used to Treat Degenerative Disease in East Lombok. Jurnal Biologi Tropis, 20(3), 423. https://doi.org/10.29303/jbt.v20i3.2119 